\title{
On the Cognitive Mechanism of Grammatical Metaphor*
}

\author{
LI Jie \\ Shantou University, Shantou City, China
}

\begin{abstract}
The previous studies of grammatical metaphor mainly emphasized its metafunctions or the classifications and identifications in discourse, and treated rankshift as its mechanism of occurrence. However, the question is "Why does the rankshift make it possible?” This paper is going to study grammatical metaphor from a cognitive perspective and will treat cross-grammatical domain mapping as its mechanism of occurrence.
\end{abstract}

Keywords: metaphor, grammatical metaphor, cognitive, mapping, grammatical domain

\section{Introduction}

By taking a socio-cultural perspective, Michael Halliday treats language as a system of meaning making resources. He claims that lexical selection is just one aspect of lexico-grammatical choice; and that metaphorical variation is lexico-grammatical rather than simply lexical. Such an idea about language leads him to put forward his famous grammatical metaphor theory. A grammatical metaphor is the result of a shift between grammatical categories. But for a long time, the previous researches of grammatical metaphor focused mainly on such issues as the metafunctions, the classifications of grammatical metaphor and its identifications in discourses. They have done little to probe into the cognitive aspects of the grammatical metaphor phenomenon, so that it seems not possible to investigate the grammatical metaphor phenomenon thoroughly, and there have heretofore not been a satisfactory explanation given to this linguistic phenomenon. This paper is going to treat grammatical metaphor as a cognitive-functional construct of linguistic representation for meaning, resulted in cross-grammatical domain mapping as its mechanism. By looking for cognitive approaches to metaphor as a theoretical basis, the author attempts to show how the cognitive perspective can throw light on grammatical metaphor and how the cognitive factors together with social functional factors may result in the occurrence of grammatical metaphor.

\section{The Cognitive Framework of Metaphor}

The awareness of metaphor as an important phenomenon is at least as old as Aristotle, but in making it the primary target of investigation for linguistics proper, Lakoff and Johnson have departed radically from the traditional views. Such a change is marked by the publication of their famous book Metaphors We Live By in 1980. The central theme of Lakoff and Johnson's theory is that metaphor, in its broad sense, is pervasive and essential in language and thought. They claim,

\footnotetext{
* Acknowledgements: This paper is one of the research results of the project (12YJA740036) founded by Ministry of Education of China.

LI Jie, Ph.D., Professor, College of Liberal Arts, Shantou University.
} 
Most people think they can get along perfectly well without metaphor. We have found on the contrary, that metaphor is pervasive in everyday life, not just in language but in thought and action. Our ordinary conceptual system, in terms of which we both think and act is fundamentally metaphorical in nature. (Lakoff \& Johnson, 1980, p. 3)

Thus, in the cognitive linguists' view, metaphor is no longer just regarded as a figure of speech, but also as an important mechanism for thought and cognition. Human conceptual systems are "pervasively structured by metaphor, metonymy, and other kinds of imaginative structure” (Johnson, 1987, p. 158). This view supports such an idea that metaphors have much to do with the systems of human conceptualization, operating deep in human thought and cognition and, at the same time, existing in everyday language in a systematic way.

Metaphor is natural in that it is motivated by the basic structure of our experience. It is believed that through experiences, we have established certain concepts in our mind and we automatically or unconsciously express ourselves under the influence of these concepts. In other words, our concepts structure what we perceive or experience; for example, how we get around in the world, and how we relate to other people. Our conceptual system thus plays a central role in defining our everyday realities. Lakoff and Johnson point out, "If we are right in suggesting that our conceptual system is largely metaphorical, then the way we think, what we experience, and what we do every day is very much a matter of metaphor" $(1980$, p. 3). What they mean is that metaphor is working in such a way as mapping one domain (or concept) onto another; for instance, as mapping "life" with our understanding about "journey” as is evidenced in LIFE IS A JOURNEY metaphor.

The cognitive linguistic theory obviously offers us a different view. It treats metaphor as a way of conceptualizing and experiencing the world and goes further than the traditional view of metaphor as a different way of expression. So the most important claim of Lakoff and Johnson (1980) is that metaphor is not just a matter of language, but of human thought and cognition. The language is secondary, while the mapping is primary in that it sanctions the use of source domain language and inference patterns for target domain concepts. The mapping is conventional; that is, it is a fixed part of our conceptual system.

Metaphor, as a cognitive tool enabling us to draw on our previous experience with familiar issues and mapping them onto less familiar ones, occupies a prominent place in our thought. The most powerful aspect of this modern metaphor theory is to ground abstract concepts in meaning indirectly through more concrete concepts. Metaphor is a very important source of structuring for many concepts (Lakoff \& Johnson, 1980). In metaphor, the structure of one domain of experience is mapped onto another domain, providing a ready-made structure for the latter domain. Cognitive linguists have found that metaphorical mappings are fundamental and ubiquitous in human thought and speech, and metaphor is a very important source of structuring for concepts. It is conceptually bound and thus influences the way we perceive, and it is hence pre-linguistic.

\section{Mapping and Metaphorical Expressions}

The cognitive linguists hold the view that language is secondary and mapping is primary. In fact, the terminology adopted in their theory can reflect the primacy of human mind, because the term "metaphor" is reserved for conceptual mappings, and "metaphorical expression" is the term for the linguistic manifestation of the mapping (Lakoff, 1993, p. 208). The mapping generates a range of metaphorical expressions in language. Systems of metaphors in language provide evidences to support the claims of conceptual metaphor, and the idea of conceptual metaphorical extensions can explain how we make sense of novel metaphors in language. 
The key notion in seeing metaphor as cognitive is the recognition that in metaphor two concepts are operative simultaneously. Lakoff uses the term "domain" to refer to the concept, and the term "mapping” to the directional interaction between the two domains. Thus a mapping is the systematic set of correspondences that exist between constituent elements of the source and the target domains. There exists a structural correlation in everyday experience between the source domain and the target domain, which motivates this particular metaphorical mapping. The general idea of metaphorical mapping is that, in order to talk or think about certain domains (target domains) we use the structure of other domains (source domains) and the corresponding terms. This transfer is called "mapping" from a source cognitive domain to a target domain, which means that “metaphor operates between domains" (Sweetser, 1990, p. 19), turning the world phenomena and concepts into embodied entities. Let's take this metaphorical mapping as an example: TIME AS SPACE. We use structure from our everyday concept of space to organize our everyday concept of time, as the following examples show: (1) Christmas is approaching. (2) The victory was just around the corner.

The mapping that metaphor performs is highly selective. It is by no means a one-to-one mapping of all the information from a source domain to a target domain. Lakoff makes a further study of mapping; and it is a study of the basic experiential structures and their properties. He points out, "Existing concepts may impose further structuring on what we experience, but basic experiential structures are present regardless of any such imposition of concepts” (Lakoff, 1987, p. 271). Lakoff and Johnson argue not only that metaphorical conceptual mappings are reflected in the expressions that we use, but also that we use these conceptual mappings to understand those expressions. According to the conceptual-mapping view, nominal metaphors are understood as specific instantiations of systematic conceptual-mappings that are part of our world knowledge. As Gibbs (1994) argues, the theory of conceptual mapping is a theory of thinking, and people conceive of ideas in many different ways.

\section{Cross-domain Mapping as Mechanism of Metaphor}

For cognitive linguists, a metaphor consists in the mapping of one domain onto another domain, and concepts may be structured or restructured through metaphorical mappings. In other words, whenever a person takes a concept that has been formed in one domain and tries to implement it in another, a metaphor occurs. Thus the essence of metaphor is understanding and experiencing one kind of thing in terms of another. Each metaphor has a source domain, a target domain, and a source-to-target mapping as well. For instance, in the PURPOSES ARE DESTINATIONS metaphor, purposes are understood in terms of destinations, and achieving a purpose is understood as going along a path from a starting point to an endpoint. There is an experiential correlation between the source domain (movement along a path to a physical location) and the target domain (achievement of a purpose). This correlation involves a mapping from the source to the target domain.

What enables us to structure our new experience by drawing upon previous experience, is our cognitive abilities to rely on already available models of thought and perception, so that "in every act of categorization we are more or less consciously referring to one or several cognitive models that we have stored” (Ungerer \& Schmid, 1996, p. 49). Cognitive linguists proclaim that metaphor is a cross-domain mapping which follows the Invariance Principle- - Metaphorical mappings preserve the cognitive topology (that is, the image-schema structure) of the source domain, in a way consistent with the inherent structure of the target domain” (Lakoff, 1993, p. 215). It means that there must be correspondences between the two domains: Source domain interiors correspond to 
target domain interiors, and source domain exteriors correspond to target domain exteriors, etc. For example, the principle is abided by the LOVE IS A JOURNEY conceptual metaphor, in which lovers correspond to travelers, romantic relationships to traveling vehicle, interpersonal problems to physical obstacles on a route, and so forth.

At the same time, the cross-domain mapping follows another principle-Target Domain Overrides (Lakoff, 1993). That is, the structure inherent in the target domain cannot be violated, because it decides what properties of the source domain can be mapped. For example, in the THEORIES ARE BUILDINGS metaphor, only the foundation and the structure of a building are mapped, but the roof, window or door of the building are not mapped because there is no correspondence in the target domain. These two principles can explain the asymmetry of metaphor. When we say $\mathrm{A}$ is $\mathrm{B}$, the properties of $\mathrm{B}$ are mapped onto the background of $\mathrm{A}$, also within the limits of A; when we say B is A, it is the opposite: The properties of A are mapped onto the background of B, also within B's limits. In such a manner, different properties are mapped onto different backgrounds, which may result in producing different meanings.

Such cross-domain mappings are realized by a number of metaphorical expressions. A major discovery of Lakoff and Johnson is that people use metaphorical expressions in a systematic way because their metaphorical concepts are organized systematically. The systematicity of conceptual metaphor may be summarized in two points:

(a) Each conceptual metaphor heads and governs a system of correspondences between the source and target domains.

(b) Conceptual metaphors may also be systematically related to each other to form a hierarchical or parallel structure.

By doing so, the entities and knowledge of the source domain are systematically mapped onto the target domain. Lakoff and Turner (1989, p. 63) explain that a metaphorical mapping of the structure of the source domain onto that of the target domain usually consists of the following: Relations, properties, and knowledge in the source domain are mapped onto relation, properties and knowledge in the target domain respectively. Many elements of target concepts come from source domains and are not pre-existing. Thus, to understand a conceptual metaphor is to know the set of mappings that applies to a given source-target pairing. The conceptual metaphor itself forms an intricate system with the correspondences between the two domains. On the one hand, conceptual metaphor itself is structured by a system of entailments; and on the other hand, it forms a part of a larger system. That is, conceptual metaphors are organized in hierarchical structures, in which "lower" mappings in the hierarchy inherit the structure of the "higher" mappings. Given below is an example of such a hierarchy included in the LOVE IS A JOURNEY metaphor (Lakoff \& Johnson, 1980, pp. 44-45).

As for the LOVE-AS-JOURNEY mapping, there are such entailments involved:
a) The lovers correspond to travelers.
b) The love relationship corresponds to the vehicle.
c) The lovers' common goals correspond to their common destinations on the journey.
d) Difficulties in the relationship correspond to impediments to travel.

Thus, they can be interpreted as:
e) Two TRAVELLERS are in a VEHICLE, TRAVELING WITH COMMON DESTINATIONS.
f) The VEHICLE encounters some IMPEDIMENT and gets stuck, that is, makes it non-functional.
g) If they do nothing, they will not REACH THEIR DESTINATIONS. 
What constitutes the LOVE-AS-JOURNEY metaphor is not any particular word or expression. It is the mapping across the conceptual domains, from the source domain of journey to the target domain of love. The mapping of the concepts between the two different domains is primary, and the language is secondary in that linguistic metaphorical expressions are derived accordingly.

\section{Mapping Across Grammatical Domains in Grammatical Metaphor}

A metaphor thus links two separate cognitive domains, by using the language appropriate to one of them as a lens through which to observe the other (Indurkhya, 1986). Through the metaphorical re-structuring of the target domain in terms of the source domain, some terms acquire a metaphorical meaning. Thus, metaphor is taken as a conceptual mapping taken place for resembling something from a new perspective. Taking the cues and clues from the cognitive linguistic theory, we can see more clearly how rankshift is made possible. The occurrence of rankshift is actually a process whereby a unit of one rank is moved to another for a certain function. Lexicogrammar is a natural symbolic system, which means "both the general kinds of grammatical pattern that have evolved in language, and the specific manifestations of each kind, bear a natural relation to the meanings they have evolved to express” (Halliday, 1985, p. xviii). The rank scale determines the basic realization patterns. There is a link between the categories of the grammar and reality. That is to say, grammar and reality are generally related in a congruent manner. Then the notion of grammatical metaphor refers to certain non-natural grammatical variations of natural grammatical structures, which is illustrated in Figure 1 (cf. LI, 2011, p. 33).

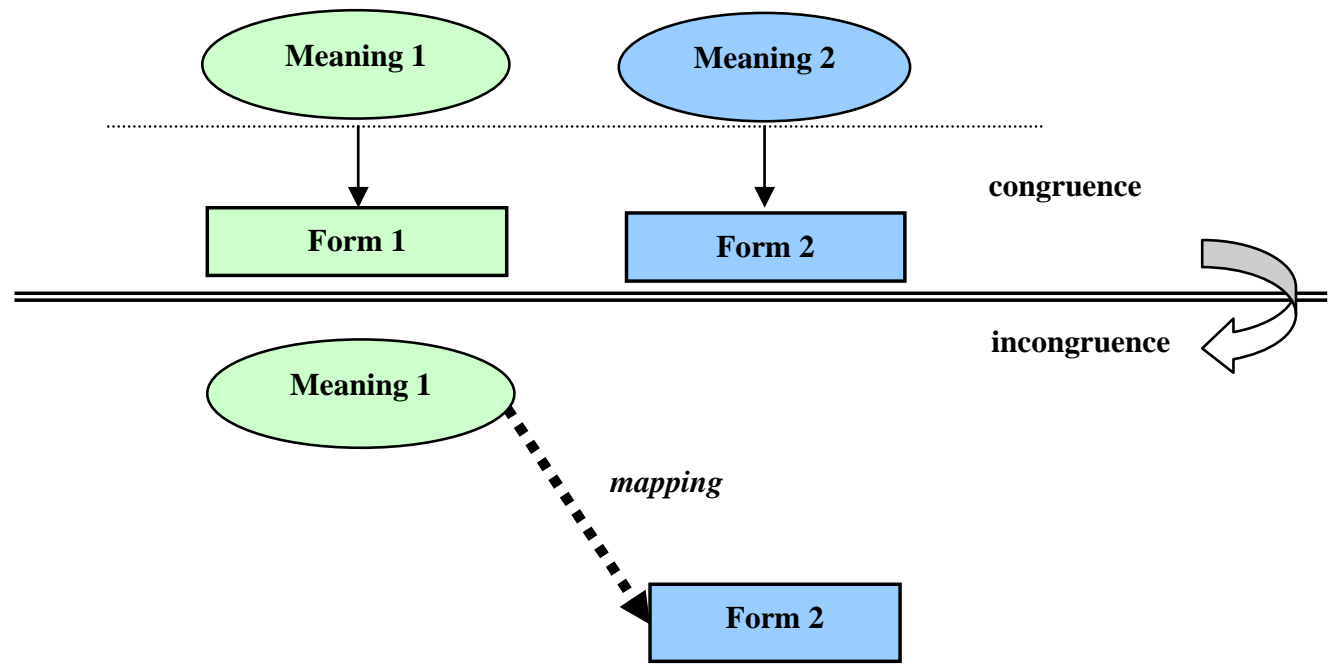

Figure 1. The metaphorical relation between meaning and form.

In this figure, we can notice that such an approach relies on the fact that there are different choices of grammatical structures. Grammatical metaphor is generally conceived as an incongruent realization of a given semantic configuration in the lexicogrammar. However, something else that can be transferred from the source to the target domain is the mode of production of variation in expression. A metaphorical expression implies a discrepancy between semantics and lexicogrammar. Meaning can be construed in different ways by means of different units of ranks or grammatical constructions. In other words, meanings may be mapped from semantically congruent grammatical structures onto semantically incongruent grammatical structures. Then, 
grammatical metaphor can be taken as a certain conceptual meaning mapped from a congruent form onto metaphorical forms, which is illustrated in Figure 2.

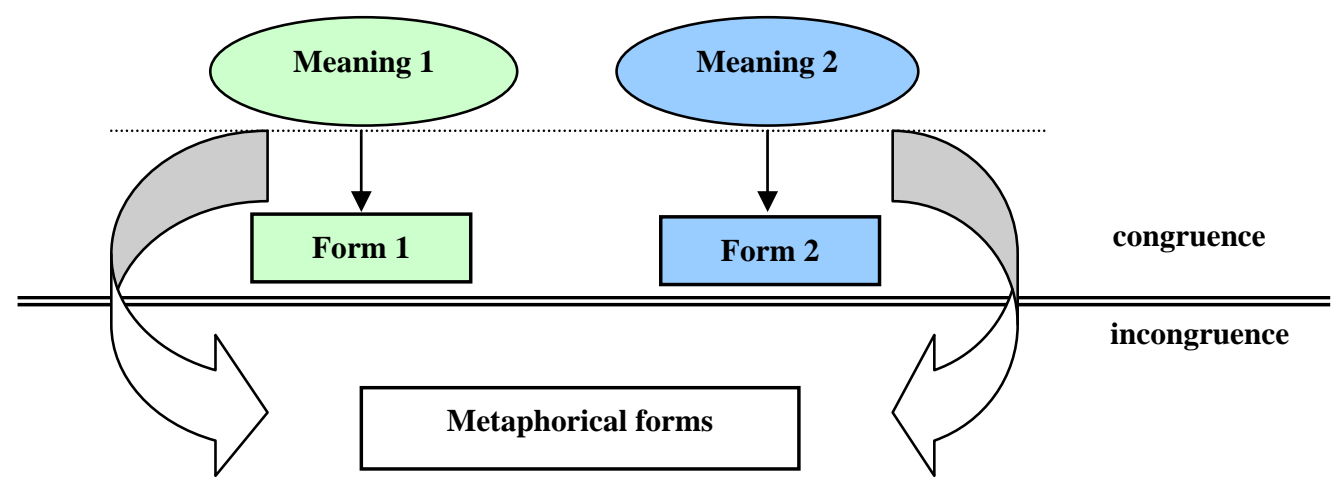

Figure 2. The mapping of meaning from congruent form onto metaphorical forms.

Therefore, the variation in form is the metaphorical extension of variations in meaning. The variation may be generated lexically from a natural meaning to an unnatural meaning. Similarly, in grammatical metaphor, the variation is achieved from the natural relation between grammar and semantic content to a metaphorical or derived forms of expression.

\section{Conclusion}

The analysis set out for this study is rooted in a view of language, which is at the same time not only functional but also cognitive. It is functional in that it builds on the assumption that the nature of the language system is "closely related to the social and personal needs that language is required to serve" (Halliday, 1970, p. 142). The language system is viewed as functional with respect to the particular needs of the language user. More specifically, the language system is claimed to be shaped by the functions that it serves. Thus, the language system is actually an integral part of human cognition. Construing language is seen as "something that speakers do" (Langacker, 1987, p. 65). Language is held to refer to "those aspects of cognitive organization in which resides a speaker's grasp of established linguistic convention” (Langacker, 1987, p. 57). The language system may provide the necessary "symbolic potential”, but it is left for the speaker to recognize the potential, i.e. to "exploit it in a fashion that responds to all the varied constraints inherent in the situation" (Langacker, 1987, p. 66). Speaking more specifically, cognitive factors are important for language users to shape grammatical structures in their mind, and with the needs of communicative purpose, the functional factors also come to play an important role in constructing lexico-grammatical forms. As a common linguistic phenomenon in human language, grammatical metaphor hence reflects the influence from social as well as cognitive factors. When metaphorical thinking is built into the linguistic representation or coding system, we are able to relate different concepts by describing one in terms of another. Accordingly, we may regard cross-domain mapping as a cognitive mechanism for generating grammatical metaphors, because grammatically metaphorical realization of meaning may be treated as a combination and mutual interaction of both the functional influence of the grammatical system of language and the cognitive mechanism of language user. 


\section{References}

Gibbs, R. W. (1994). The poetics of mind. Cambridge: Cambridge: Cambridge University Press.

Halliday, M. A. K. (1970). Language structure and language function. In J. Lyons (Ed.), New horizons in linguistics. Harmondsworth: Penguin Books.

Halliday, M. A. K. (1985). An Introduction to functional grammar. London: Edward Arnold.

Halliday, M. A. K. (1994/2000). Introduction to functional grammar. London: Edward Arnold/ Beijing: Foreign Language Teaching \& Research Press.

Indurkhya, B. (1986). Conshained semantic transference: A formal theory of metaphors. Synthese, 68(3), 512-552.

Johnson, M. (1987). The Body in the mind: The bodily basis of meaning, imagination, and reason. Chicago: The University of Chicago Press.

Lakoff, G. (1987). Woman, fire, and dangerous things: What categories reveal about the mind. Chicago: Chicago University Press.

Lakoff, G. (1993). The contemporary theory of metaphor. In A. Ortony (Ed.), Metaphor and thought. Cambridge: Cambridge University Press.

Lakoff, G., \& Johnson, M. (1980). Metaphors we live by. Chicago: Chicago University Press.

Lakoff, G., \& Turner, M. (1989). More than cool reason: A field guide to poetic metaphor. Chicago: Chicago University Press.

Langacker, R. W. (1987/2004). Foundations of cognitive grammar. Theoretical prerequisites. Stanford: Stanford University Press/ Beijing: Peking University Press.

LI, J. (2011). On the exploration of the semantic issues of grammatical metaphor. In Huang Guowen, et al. (Eds.), Forum on systemic functional linguistics studies (Vol. 2). Beijing: Higher Education Press.

Sweetser, E. (1990). From etymology to pragmatics. Cambridge: Cambridge University Press.

Ungerer, E., \& Schmid, H. J. (1996/2001). An introduction to cognitive linguistics. Addison Wesley Longman Limited /Beijing: Foreign language Teaching and Research Press. 